\title{
STUDY ON THE EFFECT OF THE TYPE OF FULL HOPPER SIGNALLING USED IN GRAIN HARVESTERS ON THE TIME FOR THE GRAIN HOPPER UNLOADING
}

\author{
Galin Tihanov \\ Department of Agricultural Engineering, Faculty of Agriculture, Trakia University \\ Studentski grad, 6000 Stara Zagora, Bulgaria \\ e-mail: galin.tihanov@abv.bg
}

\begin{abstract}
The paper has established the length of the time for unloading hoppers in harvesters using a different signaling mode for full hopper: without automatic signalling - $245.35 \mathrm{~s}$; with one level of automatic signalling - $224.5 \mathrm{~s}$; with two levels of automatic signalling - $208.82 \mathrm{~s}$ and for harvesters unloading in the vehicle located at the end of the field - $301.46 \mathrm{~s}$. Dispersion analysis has been carried out proving the effect of the type of signalling for full hopper used on the total time for unloading the hopper at a significance level of $a=0.05$. Through it the interaction between the factor: type of signalling used on the time for unloading the hopper tp has also been established.
\end{abstract}

Keywords: grain harvesters, productivity, hopper unloading time, joint operation between harvester and vehicle.

\section{INTRODUCTION}

Harvest of cereals has to be made within relatively short time so as not to allow production losses due to the extended harvesting time [1-3]. These losses, as a rule, are the greatest in unfavorable climatic conditions. The difference between biological and actual yields in some cases reaches $30-40 \%$ [4]. Moreover, some authors have identified options for growing the grain crop-wheat on soils contaminated [5]. This is supported by the fact that grains accumulate $\mathrm{Pb}, \mathrm{Zn}$ and $\mathrm{Cd}$ in amounts exceeding the maximum permissible limits and could pose a risk for human health.

The successful and timely harvesting of cereals depends both on the type of machinery used and the organization of its use. Coordination between harvesters and vehicles is carried out by means of harvester signallisations for hopper filling [6].

In harvesters without automatic signalling or older generations of harvesters the hopper filling is monitored through an observation window. A signal to the vehicle driver is given by stopping the grain harvester and opening its unloading screw [7].

In harvesters with single level of signalization for full hopper, signaling lamp or buzzer in the cabin informs the operator about filling the grain hopper and simultaneously an external signal lamp is switched on to inform the vehicle driver. When unloading with the harvester exiting at the edge of the field, the signaling for full hopper is not used. All manufacturers (in single level signalling harvesters) recommend the signaling device switch to be switched on before the hopper is filled to allow it to take additional amount of grain until unloading begins [8]. Naturally, the precise timing of switching on cannot be achieved, especially when harvesting on slopes.

In harvesters with two levels of signaling for full hopper, the switching of the first level of the harvester signal lamp is to inform the vehicle driver about forthcoming filling of the hopper. The harvester continues to reap until filling the hopper. Upon reaching the second level, 
sound and light signaling is switched on in the cabin, alerting the driver to stop the harvest (full hopper).

These levels are usually controlled by sensors mounted in the harvester hopper, whose position can be adjusted [2]. It is very important to determine their exact position. When adjusting the second level sensor the aim is to use the grain hopper more thoroughly without allowing overflowing or adjusting to a specific volume according to the vehicles. The first level sensor is adjusted so that after the given signal there should be enough time for the vehicle to reach the harvester, at that, at the moment of filling the hopper to the second level, i.e. when the harvester has to stop for unloading. Practically, it co-ordinates the joint operation between grain harvesters and transport vehicles. The lack of such coordination (synchronization) is a prerequisite for idle time that lead to an extension of the harvest period [9].

In order to increase productivity various technical devices are used in modern grain harvesters. They help to optimize hopper unloading operations and reducing total time. This can be achieved by information on the duration of unloading idle times by using telematic systems-AgCommand Advanced; CLAAS Telematics; JDLink Ultimate; Connected Farm and AFS Connect Executive [10].

The objective of this paper is to study the signalling used for full hopper of grain harvesters and to determine their impact on the times for unloading the grain hopper.

\section{MATERIAL AND METHODS}

Studies were conducted during the harvest campaign of 2018 on 16 farms. One grain harvester was selected on each farm. On all farms, the unloading of the grain hopper was carried out in stopped position of the harvester. The study focused on four variants for unloading harvester hoppers at standstill depending on the type of signalling used. By dispersion analysis was assessed the effect of the type of full hopper signalling (factor $A$ ) on the unloading time of the hopper-tp [11]:

$a_{1}$ - harvesters without automatic signalling;

$a_{2}$ - harvesters with one level of automatic signalling;

$a_{3}$ - harvesters with two levels of automatic signalling;

$a_{4}-$ harvesters unloading in the vehicle located at the end of the field. Stopping harvesting and heading towards the end of the field is a signal for full hopper.

In each of the variants of the monitored grain harvesters the time for unloading the grain hopper was measured - tp, $s$. This is the period of time since the harvester stopped harvesting after filling the hopper until resuming harvest after the hopper was emptied, that is, the time when no productivity is achieved. The measured duration is defined by its minimum, maximum, mean value, mean square deviation and limit relative error at $\gamma=0,9$ [11].

\section{RESULTS AND DISCUSSIONS}

Table 1 presents the summarized results of the time measured for hopper unloading of grain harvesters using different type of full hopper signalling. It shows that its average duration is $245.03 s$, varying from $123 s$ to $352 s$ in the various options. It can be seen that the relative error at $y=0.9$ is within the permissible limits. 


\section{IRTITE}

Ipplied Reseirl'ches in Technics, Technologies and Bducation Journal of the Faculty of Technics and Technologies, Trakia University https://sites.google.com/a/trakia-uni.bg/artte/

Table 1. Time of unloading of the grain hopper of harvesters using a different type of full hopper signalling

\begin{tabular}{|c|c|c|c|c|c|c|c|c|}
\hline \multirow{2}{*}{$\begin{array}{l}\text { Type of } \\
\text { signaling } \\
\text { used }\end{array}$} & \multirow{2}{*}{$\begin{array}{c}\text { Number of } \\
\text { harvesters } \\
n\end{array}$} & \multirow{2}{*}{$\begin{array}{c}\begin{array}{c}\text { Number of } \\
\text { measurements }\end{array} \\
N\end{array}$} & \multicolumn{3}{|c|}{$\begin{array}{l}\text { Duration } \\
t p, s\end{array}$} & \multicolumn{3}{|c|}{ Indicators } \\
\hline & & & $X_{\min }$ & $X_{\max }$ & $\bar{X}$ & Variance & $\begin{array}{l}\text { Std. } \\
\text { Dev. }\end{array}$ & $\begin{array}{l}\text { Standard } \\
\text { error }\end{array}$ \\
\hline$a_{1}$ & 3 & 20 & 185 & 297 & 245.35 & 888.55 & 29.81 & 6.67 \\
\hline$a_{2}$ & 3 & 18 & 182 & 264 & 224.5 & 544.38 & 23.33 & 5.49 \\
\hline$a_{3}$ & 8 & 93 & 123 & 287 & 208.82 & 806.68 & 28.40 & 2.94 \\
\hline$a_{4}$ & 2 & 15 & 231 & 352 & 301.46 & 1066.41 & 32.65 & 8.43 \\
\hline
\end{tabular}

Figure 1 graphically presents the time for hopper unloading in various harvesters. It shows that there is a huge difference in the duration of $t p$ in various harvesters, due to lack of coordination in the actions of the operators of harvesters and vehicles, as well as incorrect setting of the sensor for first level of hopper fillingr. Higher values of time tp result in lower productivity. Subjective factors (operators) have a serious effect on the unloading time inside the field and, respectively, on the productivity of grain harvesters.

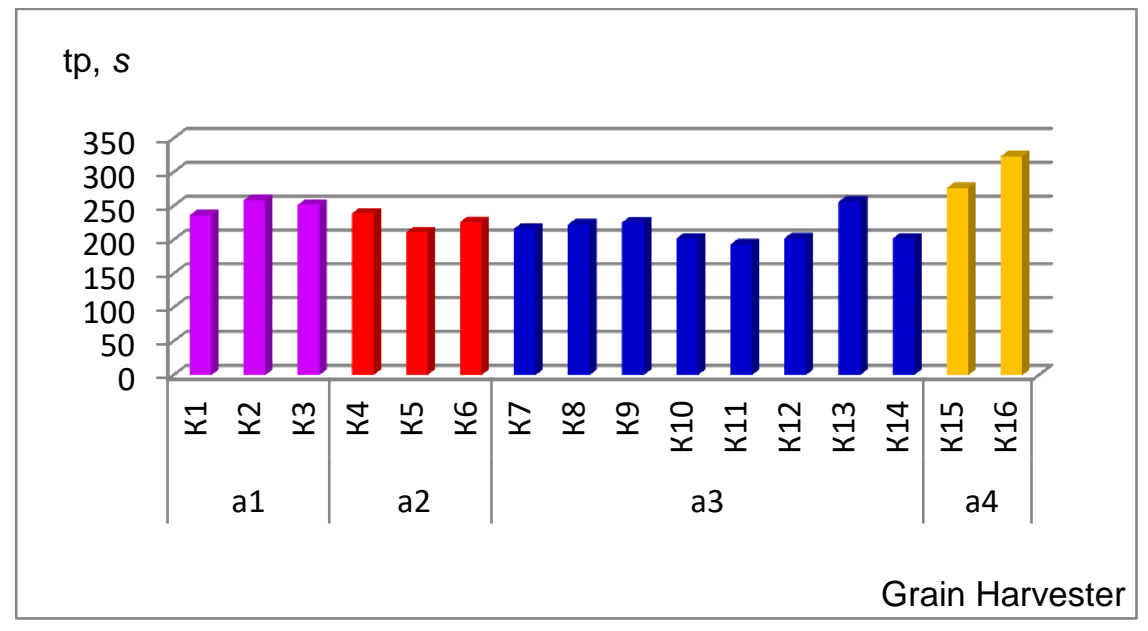

Figure 1. Time for unloading the grain hopper of the various grain harvesters using different type of full hopper signaling

Table. 2 presents the results of the dispersion analysis of the effect of the type of signalling used on the time of hopper unloading, and their graphic presentation is given in Figure 2.

Table 2. Results of the dispersion analysis of the effect of the type of signalling used on the time of unloading of the grain harvester hopper

\begin{tabular}{|c|c|c|c|c|c|}
\hline \multirow[b]{2}{*}{ Effect } & \multicolumn{5}{|c|}{$\begin{array}{l}\text { Univariate Tests of Significance foitp (Spreadsheet1 } \\
\text { Sigma-restricted parameterization } \\
\text { Effective hypothesis decomposition }\end{array}$} \\
\hline & SS & $\begin{array}{l}\text { Degr. of } \\
\text { Freedom }\end{array}$ & MS & $\mathrm{F}$ & $p$ \\
\hline Intercept & 5250356 & 1 & $525035 €$ & $6467,18 \varepsilon$ & 0,00 \\
\hline A & 120305 & 3 & 40102 & 49,396 & 0,00 \\
\hline Error & $11528 \varepsilon$ & 142 & 812 & & \\
\hline
\end{tabular}

IRTIIE Vol. 6, No. 4, 2018 ISSN 1314-8788 (print), ISSN 1314-8796 (online), doi: 10.15547/artte.2018.04.002 


\section{IRTTL $\vee$}

Ipplied Reseirl'ches in Technics, Technologies and Bducation

Journal of the Faculty of Technics and Technologies, Trakia University https:///ites.google.com/a/trakia-uni.bg/artte/

The table shows that the effect of the type of signaling used on the unloading time has been proven, since probability $p$ is much less than the significance level $a=0.05$.

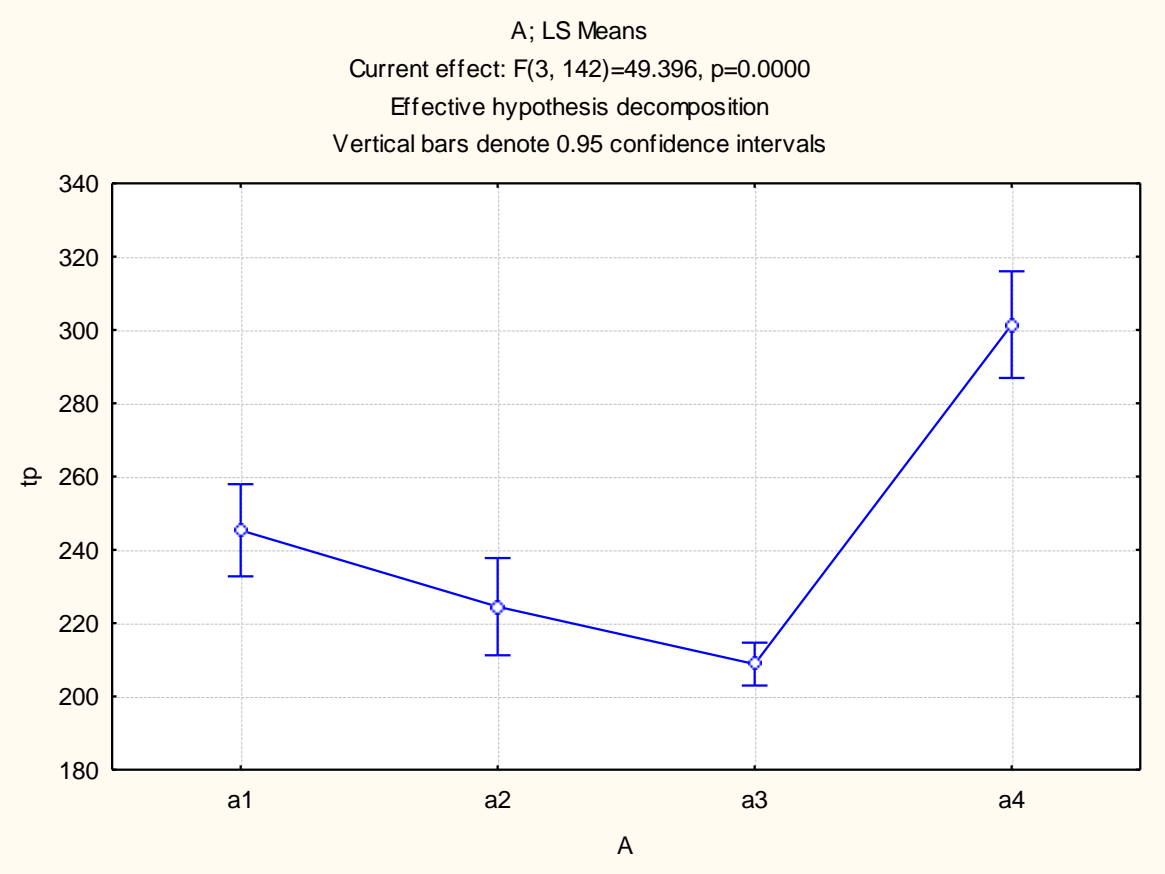

Figure 2. Effect of the type of signaling used (factor A) on the time of unloading the grain hopper tp of grain harvesters using the different type of signalling for full hopper tp

Figure 2 shows that in the first variant $a_{1}$ (harvesters without automatic full hopper signalling) unloading time is $245.35 \mathrm{~s}$ on average. This high duration was due to the fact that the lack of full hopper signalling resulted in considerable waiting time for the vehicle. In the second option $\mathrm{a}_{2}$ (harvesters with one level of automatic signalling), time is significantly lower than the variant $\mathrm{a}_{1}$, with an average duration of $224.5 \mathrm{~s}$. This is due to the presence of signalling for one level of harvester hopper filling. Also, in this variant the hopper volumes in the different harvesters were of less capacity. In the third variant $a_{3}$ (harvesters with two levels of automatic signalling), it can be seen that time tp is minimum $208.82 \mathrm{~s}$. The reason for this is that with the two-level signalling for hopper filling sufficient time for movement of the vehicle is provided. In the fourth variant $a_{4}$ (harvesters unloading in the vehicle at the edge of the field), the duration of tp is the highest, $301.46 \mathrm{~s}$ on average. It is logical for this mode of unloading time tp to be much longer than the other three variants as the harvester after filling its hopper moves to the vehicle that is at the edge of the field and returns to the bed to continue the harvest.

Figure 3 graphically represent the results of the dispersion analysis of the interaction between the type of signalling used in various grain harvesters on the time of hopper unloading-tp. 


\section{ARTTIE $Y$}

Ipplied Researroches in Technics, Technologies and Eductition Journal of the Faculty of Technics and Technologies, Trakia University https://sites.google.com/a/trakia-uni.bg/artte/

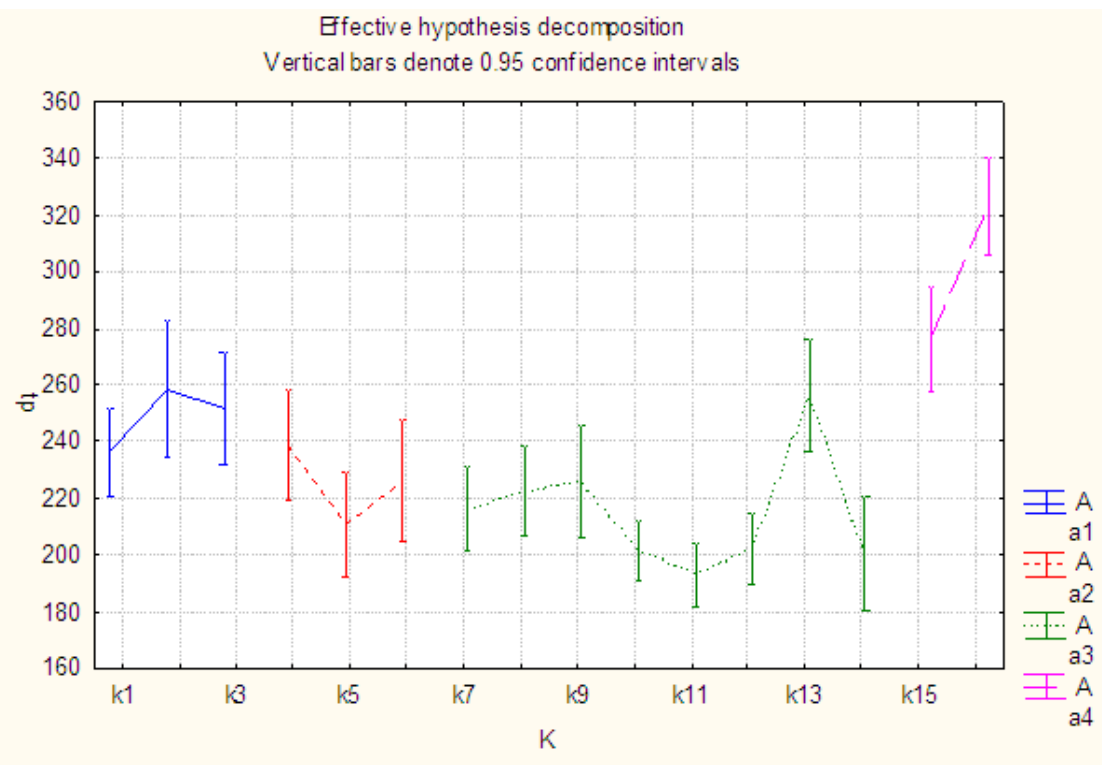

Figure 3. Time for unloading the grain hopper of the various grain harvesters using different type of full hopper signaling

\section{CONCLUSIONS}

The duration of the unloading time of hoppers tp has been determined in harvesters using different mode of full hopper signalling:

- without automatic signalling - $245.35 s$;

- with one level of automatic signalling - $224.5 \mathrm{~s}$;

- with two levels of automatic signalling $-208.82 \mathrm{~s}$;

- unloading in the vehicle at the edge of the field $-301.46 \mathrm{~s}$.

Through the dispersion analysis, the effect of the type of full hopper signalling used on the unloading time of the harvester hopper was demonstrated. The explanation is that the probability $p$ is less than the significance level $a=0.05$.

As a result of the dispersion analysis, the effect of the type of signalling used on the time of unloading of the harvester hopper was determined.

In order to minimize the total unproductive time in the process of unloading the grain harvester hopper and consequently to increase the actual shift performance, it is necessary to apply strict organizational and work discipline, as well as the use of appropriate harvesting and transportation machinery, corresponding to the characteristics of the fields and the harvested crop.

\section{REFERENCES}

[1] Delchev N. \& Trendafilov K. (2013). Method for rapid determination of the percentage rate of grain losses by the combine harvester according to its parameters, Agricultural science and technology, Vol. 5, No. 1, March 2013, 62-64.

[2] Tihanov G. (2017). Study on the time of unloading of grain harvester hoppers at standstill in relation to optimization of their productivity, Dissertation paper for awarding Doctor's educational scientific degree, Ruse University "Angel Kanchev", Ruse, 2017, $140 \mathrm{p}$.

[3] Trendafilov K. \& Dragoev D. (2017). Study on the effect of the place of unloading of the grain hopper on the grain harvester productivity, International Scientific Conference IRITIE Vol. 6, No. 4, 2018 ISSN 1314-8788 (print), ISSN 1314-8796 (online), doi: 10.15547/artte.2018.04.002 


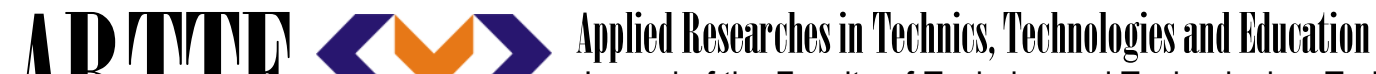 Journal of the Faculty of Technics and Technologies, Trakia University https://sites.google.com/a/trakia-uni.bg/artte/}

"Technics, Technology, Education" ICTTE 2017 of the Faculty of Technics and Technologies of Yambol, Trakia University, Stara Zagora, 19-20 Oct 2017, Proceedings, 26-31.

[4] Vasilev K. (1987). Industrial technologies in agriculture, Higher Technical School "Angel Kanchev", Ruse.

[5] Ivanova M., Dospatliev L., Stoyanova A. \& Valchev N. (2017). Possibilities of wheat farming on soils contaminated with heavy metals in the region of NFMW-Plovdiv, Bulgaria. Applied Researches in Technics, Technologies and Education, Volume 5, No. 2, 131-142.

[6] Tihanov G., Kolev B., Trendafilov K., Delchev N. \& Stoyanov Y. (2017). Justification of the method for determining the moment for switching on the level one signaling of filled grain harvester hoppers, Agricultural science and technology, Volume 9, No. 3, September 2017, 218-222.

[7] Delchev N. \& Trendafilov K. (2015). Structural Analysis of the Operations and Time for Tank Unloading of Grain Harvesters, International Journal of Science and Research (IJSR), Volume 4, Issue 3, March 2015, 1890-1894.

[8] Isaacson H. I. (1974). Grain harvesters "Niva" and "Kolos", Moscow.

[9] Mihov M. (2013). Mathematical model for optimization of the operation of servicing machines in harvesting production, Agricultural Mechanization No. 6, 11-15.

[10] "Telematics: Wireless Communication and Data Transfer". (2012). Precision Agriculture Series, Timely Information, Agriculture, Natural Resources \& Forestry, Alabama Cooperative Extension System, September 2012, [Online], Available: www.AlabamaPrecisionAgOnline.com.

[11] Mitkov A. (2011). Theory of the experiment, Ruse, Dunav press. 